\title{
18
}

\section{Time and temporality in global governance}

\author{
Terence C Halliday ${ }^{\top}$
}

\section{Introduction}

The politics of global governance and regulation occur in time. To say so is a truism, even ingenuous. To disentangle the manifestations of temporality, however, is another matter. The intricacies of politicallegal action too often are taken for granted. They lie beneath the surface where undercurrents influence processes and products of globalisation and resistance, where their invisible dimensions hide sweeps of history, imprints of events and manifestations of power. To understand how global norms and standards are produced, to anticipate when transnational legal

1 I express my indebtedness to my co-authors in five research collaborations that inform this essay: Lucien Karpik and Malcolm Feeley on struggles through grand time and events by the legal complex for political liberalism in South Asia, South-East Asia and Africa (Halliday et al. 2012); Bruce Carruthers on international lawmaking and national reforms in East and South Asia following the East Asian Financial Crisis (Halliday and Carruthers 2009); Michael Levi and Peter Reuter on global regulation of money laundering and the financing of terrorism (Halliday et al. 2014); Susan Block-Lieb on the making of trade and commercial law for corporate insolvency, secured transactions and carriage of goods by sea by the UN Commission on International Trade Law (UNCITRAL) (Block-Lieb and Halliday, forthcoming); and Gregory Shaffer on the rise and fall of transnational legal orders in financial regulation, business law and human rights (Halliday and Shaffer 2015a). 
orders will rise or fall, to anticipate if the power of global hegemons will succeed, it is imperative to develop systematic approaches to time and temporality in all studies of globalisation, governance and regulation.

The sociological significance of time has a rich heritage, from the sweep of historical sociology over the very long term (Braudel 1996; Karpik 1998; Putnam et al. 1993) to the microdynamics of power in queuing (Schwartz 1975) and the manipulation of sequences through time (Abbott 2001). To bring time more integrally into the understanding of governance and regulation in the late twentieth and early twentyfirst centuries, I make two principal arguments. First, it is necessary to distinguish between grand time (longue durée) and events (événements) because each entails a different scale of explanation and each offers complementary methods of inquiry (Halliday and Karpik 2012). Second, despite the apparent constancy and fixity of time, its seeming metrical precision and rigidity, the manipulability of time and temporality is integral to the micropolitics and macropolitics of global norm making and resistance. To support both propositions, I draw on reanalysis of my empirical research at the centres and peripheries of the global North and global South.

\section{Grand time}

In their magisterial work, Braithwaite and Drahos (2000) show repeatedly that global business regulation in the late twentieth century has roots in ancient or medieval common law or continental civil law. Their imprints may not be seen, yet they continue to be felt on bankers in Frankfurt or Tokyo, on shippers in China and West Africa and on traders in the southern cone of Latin America.

The scale of grand time varies enormously. In its most expansive form, the longue durée can be attached to epochs of history, whether the contours of great empires (Roman, Mughal, Ottoman, British, Spanish), the reigns of religions (medieval European Christianity, South-East Asian Buddhism), pervasive ideologies (for example, liberalism in politics and economics) or the shape of regions over many centuries (Braudel's Mediterranean). 
Grand time may be punctuated or bracketed by great historical moments, such as the fall of the Roman Empire, the Protestant Reformation, the collapse of the Qing Dynasty, the Spanish Conquest of Latin America, the Great War or the long postlude to World War II that ushered in decolonisation and eras of human rights.

When students of global governance or national regulation and local legal consciousness seek understanding of the contemporaneous in Burma or Brazil, New York City, Geneva or Washington, DC, the theory and methodology of grand time compel them to situate the present in the deep currents of ideological and material continuities, long-enduring fundamentals of political and economic institutions and persistent configurations of superordination and subordination, whether of politics, markets, social relations or mentalities. The methodology of grand time attends to the long arcs of history, which leave enduring residues. Understandings of property or trade, of protection and freedom, of rights and duties, of probity and corruption, not to mention institutions, which entrench such understandings, can enable or constrain global governance and the permutations of international regulation.

Within these epochs of grand time lie episodes of lawmaking and regulation that stretch over many years or decades. Recent theory on legal change in global contexts (Halliday and Carruthers 2007b) and transnational legal orders (Halliday and Shaffer 2015a) proposes that any given issue of governance or regulation on human rights, the environment or financing of terrorism cannot be properly understood without comprehending earlier episodes of efforts to solve longstanding issues of environmental degradation, violence against women, dehumanisation of races and religion, genocide, taxation across borders, bankrupt companies or financing of trade-to name but a few. To make sense of what is happening now, it is necessary to map temporally and dynamically those earlier episodes of norm making and implementation that produced or failed to produce lasting transnational legal orders. For instance, the powerful impetus from the World Bank to reframe the rule of law as an institution to construct vibrant markets will be grossly misunderstood unless it is seen to be in tension with earlier episodes of global norm making and implementation that are grounded in universal human rights and protections against predatory rulers. Without knowing about prior episodes of maritime legal orders that stretched from the nineteenth century to the 1980s, it is impossible to 
recognise either the significance or the contingencies of the Rotterdam Rules-a set of current global reforms applying to carrying goods to market across oceans.

Halliday and Shaffer (2015c) posit that episodes of lawmaking that lead to the rise or fall of transnational legal orders will be situated in unfolding temporalities where impulses for change emerge, frequently over long periods. To look back and explain the onset of a new episode of global norm making and regulation, or to look forward and predict why a longstanding regulatory order might disintegrate, scholars in politics, law and sociology point to facilitating factors that may include:

(1) a growing mismatch between national regulation and global markets in light of changes in economic interdependence; (2) changes in the interests and power configurations of nation-states and other actors regarding the demand for and content of transnational legal ordering; (3) shifts in ideas and the conceptualisation of problems shaping the regulation of economies and political institutions; (4) technological change, industry inventions, and developments in the organisation of business; and (5) the unintended consequences of existing transnational legal orders. (Halliday and Shaffer 2015b: 32)

Within the nation-state, developmental political scientists have construed the embeddedness of current national political options in terms of a long sequence of earlier events as path dependency. The longer the sequence, roughly speaking, the more entrenched is the configuration of institutions and behaviour. This treatment of states corresponds in broad contours with studies on organisations. The form of an (international) organisation at the time of its founding, and the reinforcement of its natal form over time, can render organisations inertial and inflexible, thereby inhibiting their capacity to adapt to changing circumstances, to new competition or to a drying up of resources. The liability of newness for a neophyte organisation, such as the United Nations Commission on International Trade Law (UNCITRAL) in the 1960s, has its analogue in the liability of age for an entrenched organisation, such as the UN International Institute for the Unification of Private Law (UNIDROIT), which was founded in 1926 (Block-Lieb and Halliday 2016).

While grand time exerts a long effect, those impacts can be mixed. It is true that national path dependency and organisational inertia, reinforced by accretions of time, can strictly limit parameters for contemporaneous decision-making. Imaginations may be stunted, organisational processes can be ossified, bases of legitimation can be outdated and the dead 
hand of history stunts adaptation and threatens even survival. At the same time, history can provide its own legitimation. A competitor to the International Maritime Committee, for instance, is unimaginable. Entrenched infrastructures elaborated over decades present potential competitors with start-up costs that can be impossible to bear.

\section{Events}

Any given episode of global lawmaking occurs also in compact time or discernible events (événements) (Halliday and Karpik 2012). These interludes, even if they unfold over several years, represent a short span in which particular actors and their strategies and tactics can be carefully observed and parsed. Studies of key events make it possible to:

delve deeply into issues of language and power, of dramaturgy and discourse, of narratives and counter-narratives, of nuance and interpretation, of scripts and actors, of doctrine and cases, of national currents and local variations. (Halliday and Karpik 2012: 17)

Here the long sweep of grand events can be traced through intricacies of particular moments. The seeming inexorability of the longue durée yields to the actuality and appearance of human agency.

Intensive studies of moments in time may be artificially segregated into interactions of exterior and interior components. Exterior components are readily identified in episodes of legal change as precipitating events, frequently in the form of crises. Although financial reforms were increasingly needed in South-East Asian countries during the explosive economic growth of the Asian Tigers during the 1980s and 1990s, it was financial crisis - the East Asian Financial Crisis- that spurred the International Monetary Fund (IMF) and the World Bank, together with the Asian Development Bank, international lenders and global financial powers, to trigger entire new episodes of global financial regulation. The fall of the Berlin Wall demonstrates the shock value of a geopolitical crisis for reconstruction of Central and Eastern European economies, just as the Nuremburg Trials and the genocides in the Balkans, Sudan and Rwanda spurred erection of international institutions of humanitarian law. The severe acute respiratory syndrome (SARS) and AIDS epidemics of the 1990s and 2000s stimulated responsive regulatory orders to health crises just as the slower moving but much more fundamental environmental 
crisis, signalled by growing evidence of the disappearance of the ozone layer over Antarctica, energised international norm entrepreneurs who crafted the Montreal Protocol.

But less momentous events can also trigger the rise or fall of new regulatory and legal orders. Sometimes it occurs when a powerful state experiences a shock, such as the 11 September 2001 attacks, or the far less remarkable but nonetheless far-reaching influence of an unexpected judicial decision, such as the US Supreme Court decision in Sky Reefer, ${ }^{2}$ which precipitated a powerful worldwide movement to redesign the rules governing international trade by sea. Even less perceptible are outbreaks of competition among international organisations, as when, for instance, the World Bank and the UNCITRAL almost came to diplomatic blows over whose international principles or rules would constitute the 'gold standard' for governance of business failures within states or across national jurisdictions.

When empirically grounded theory of globalisation combines analyses of grand time and events, powerful, layered explanations of legal orders emerge. The worldwide struggles of the legal complex over the ideals of political liberalism, which can be observed explicitly in early modern Europe-whether in seventeenth-century Britain or eighteenthcentury France-became internalised in contradictory ways within Britain's colonial Raj, and ramified across decades of postcolonial India, punctuated by critical events, such as Mrs Gandhi's 'Emergency' in 1973. Indeed, the historically contextualised struggles of British post colonies to institutionalise legal orders that can be characterised as politically liberal or despotic all turn on interplays of movements and events arrayed on temporal scales of varying length and speed (Halliday et al. 2012).

\section{The micropolitics of time and power: Making global norms ${ }^{3}$}

Grand time and momentous events (as history and event) can appear inexorable and substantially unalterable, subject to minor direction by individual and collective actors, but nonetheless flowing in such broad and strong currents that their own momentum carries most prospects of

$2 \quad$ Vimar Seguros y Reaseguros, S. A.v. M/V Sky Reefer, 515 U.S. 528 (1995).

3 This section draws heavily on Block-Lieb and Halliday (forthcoming: Chapter 5). 
human agency before them. But actors in global governance do exercise agency and they can do so in part through creative adaptations to the finitude of time.

In the United Nations, for instance, norm making confronts two sets of scarcities of time. On the one hand, much UN production depends on volunteers-activists, professionals, industry leaders-who are prepared to devote long unpaid hours to drafting and meeting, quite apart from their costs of travel and accommodation. On the other hand, the United Nations itself has a scarcity of space and translation capacities. There are only so many meeting rooms in New York and Vienna, and all official proceedings must be translated into the six official UN languages: English, French, Spanish, Russian, Chinese and Arabic. The constraints of space and translation affect how much time the United Nations can afford to devote to the governance efforts of any its agencies and groups.

Much of the micropolitics inside global lawmaking, therefore, is directed towards the transformation of time as a rigid metric or temporal constraint into a resource that is malleable and manipulable. Individual and collective actors in global lawmaking exercise power by converting clock or calendar time into new constructions of temporal action. They seek to circumvent the constraints of space and language by finding time in other places and mitigating costs for volunteers by proceeding at other paces.

Research on lawmaking in a global quasi-legislature (UNCITRAL) reveals at least five temporal tactics.

\section{Staging time}

Staging time refers to the influence on the moment of onset of a lawmaking episode. Here, actors may be able to speed up or slow the temporal moment of beginnings to negotiations and lawmaking-to hurry when competitors threaten to preempt jurisdiction or to delay when prudence requires that some other event occurs or set of norms be released before an actor proceeds with its own.

For instance, in the late 1990s, UNCITRAL sped up the onset of its lawmaking on secured transaction law when it became aware that a rival lawmaking body, UNIDROIT, based in Rome, might claim that it was the legitimate international organisation (IO) to write new global law of very wide legal scope across a huge spectrum of secured financial 
transactions. UNIDROIT had already had great success in developing new global norms on a narrow front: the Cape Town Convention on Security Rights in Mobile Equipment. Energised by its success, UNIDROIT might preempt UNCITRAL, its friendly rival global legislature. Anticipating this move, UNCITRAL sprang into action, 'commissioned' a private US industry body to draft global norms of wide legal scope and placed this draft before its standing working group essentially to stake out territory before UNIDROIT had time to act.

By contrast, UNCITRAL's working group on corporate insolvency felt compelled to slow its official take-off of deliberations on a legislative guide for nation-states across the world. Energised by their rapid drafting consensus on the Model Law on Cross-border Insolvency, norm entrepreneurs set their sights on a quick pivot towards a much more ambitious effort of expansive legal scope. A colloquium to reconnoitre the prospects for a comprehensive legislative guide exceeded all expectations of reaching international consensus. At that very moment, however, the World Bank signalled that it was drafting its own norms. Afraid that the World Bank might preempt or marginalise the much weaker UN body, UNCITRAL essentially put its take-off on hold until it could take the measure of how the 'territory' of lawmaking might be divided between the bank and UNCITRAL.

The power to alter staging in this and similar cases rests principally with the strong: high-impact delegations, the availability of resourcerich non-governmental organisations (NGOs) ready to offer extensive expertise and an agile IO secretariat with a broad repertoire of legal technologies from which to choose.

\section{Compressing time}

Compressing time is a tactic for shortening the period of decisionmaking. Here, actors who control a calendar or who exert substantial power can reduce the amount of time available to inject urgency, to reduce the probability of alternative agendas or solutions and to exclude actors who are not at the centre of communication networks or whose problems of collective action preclude rapid mobilisation.

One form of compressing time, the fast start, can be observed in UN deliberations. At UNCITRAL, it was conventional to begin a new episode of global lawmaking with a colloquium at which issues were put on the table and an agenda was mapped out. Then a working group 
would begin to divide up a lawmaking area into separate categories, discussions would begin that would lead to drafting, then refinement of drafts and ultimately consensual acceptance of drafts. But the transport working group decided that any new convention-which in the past had taken an average of six years to develop-might be marginalised or overtaken by regional fragmentation or by the emergence of a radically new concept of governing the carriage of goods from manufacture to market that was preferred by the UN Conference on Trade and Development (UNCTAD). UNCITRAL's secretariat, with the support of some leading delegations, including that of the United States, charged a private organisation, Comité Maritime International (CMI), the acknowledged leader in international lawmaking for carriage of goods by sea since the late nineteenth century, with supercharging the start of proceedings by developing a draft treaty or convention that was placed on the UNCITRAL working group's agenda at its very first meeting. Some delegates believed this potentially controversial move shaved years off negotiations.

Another fast start was enabled when UNCITRAL's working group on insolvency divined through a colloquium that a surprising degree of consensus already existed across legal families on the core principles of bankruptcy norms for the world.

The power to compress time in UNCITRAL likewise relied on a coalition of strong delegations and a well-established non-state organisation. To the extent that such compression required a reallocation of resources within the United Nations-access to scarce meeting rooms, increased secretariat infrastructure-it also required effective bureaucratic politics. The stimulus to compress time, however, may lie within the power of the weak, because if coalitions of states or initiatives of regions to fragment global norms made credible threats to 'exit' from the primacy of a given global lawmaking proceedings, a prime adaptive response by the global body would be to speed up proceedings.

\section{Expanding time}

Expanding time involves lengthening the period of decision-making in calendar time from a three-year project, for instance, to five or six years. This may occur to ensure a result when issues are particularly divisive, to attenuate proceedings in the hope they will stalemate or to provide a more elaborate product with layers of norms or wider reach. It may be 
that the projected deliberations that have extended the Doha Round on intellectual property illustrate the threat that without appropriate concessions a large bloc of states can extend indefinitely the prospect of global consensus.

However, the absolute quantum of actual hours spent in deliberation can also be achieved by expanding the number of hours available in formal proceedings while holding calendar time constant. Leading delegations in UNCITRAL's Transport Working Group realised quite quickly that their formal meeting sessions, which occurred each year for one week in New York and one week in Vienna, were simply too infrequent to handle the volume of work and intensity of negotiations required to get out a new multilateral treaty before it was preempted by competing efforts. Hard-driving delegations and the UNCITRAL Secretariat persuaded the working group and commission that it must meet for two weeks, twice a year, to achieve in three years what might otherwise have taken six years.

Another way of expanding time is a variant on segmenting time (see below). If negotiations prove particularly difficult on a topic then it can be excerpted from negotiations and held over for some future regulatory or lawmaking project. Deferral essentially transforms one block of lawmaking time into two sequential blocks.

\section{Segmenting time}

Segmenting time involves the temporal partition of global governance and regulation making so that norm-making responses are segmented and sequenced. Segmentation sometimes serves a strategy of incrementalism in global lawmaking (Hathaway 2005). While both the empirical consequences and the normative debates over the merits of incrementalism continue in lively fashion across all domains of global norm making, it is useful to distinguish among three types of incrementalism: pyramidal, vertical and horizontal (Block-Lieb and Halliday 2007). Vertical incrementalism follows a strategy of small but successful steps that build on earlier successes at lawmaking to thereby develop confidence in the lawmakers, to forge collegiality in lawmaking communities and to obtain legitimation.

The area of corporate bankruptcy law had for decades been considered too challenging for global legislatures because bankruptcy law was thought to be too deeply entrenched in the particularisms of national 
legal cultures and economic histories. Globalisation of trade and markets, however, proceeded in tandem with the expansion of multinational corporations that owned assets in many countries. Further growth in world trade, it was said, required orderly ways to handle corporations in financial distress, especially when they were involved in cross-border trade. Rather than take on the full spectrum of issues that comprehensive national bankruptcy laws conventionally embrace, UNCITRAL's secretariat, international professional societies and some hard-driving delegations from Australia, the United States and France decided UNCITRAL must begin with a very small first step: a procedural model law that would not be binding on countries and would simply provide some rules about how a cross-border corporate bankruptcy might be handled by companies, professionals and courts. The relatively quick success of the Model Law on Cross-border Insolvency emboldened its norm entrepreneurs and UNCITRAL to consider a more ambitious second step. UNCITRAL's insolvency working group decided to write a legislative guide for domestic corporate bankruptcy law. In so doing, however, it deferred until step three a risky project where law was quite underdeveloped-that is, on how to handle corporate groups in financial distress. And it delayed further to step four and beyond areas where controversy was likely to be intense-for example, whether company directors should be liable for the debts of their companies in some circumstances. The partition and sequencing of global norms thereby have led to five products, each building on the other and each punctuating time with periodic successes to maintain momentum and fuel norm-making ambitions.

Segmentation sometimes serves forces of reaction, because breaking a larger task in a finite period into many smaller products or decisions invariably amplifies the time for each and thereby extends the decisionmaking process. This can be a useful strategy of resistance by the weak, as we see below.

\section{Multiplying time}

Multiplying time involves slicing decision-making episodes into finer tracks. This approach offers a creative adaptation for IOs with few or no options to extend time or which have severe constraints on the costs of deliberation. Time can be multiplied by creating parallel or 
simultaneous tracks so that different topics are allocated to different groups, unofficial meetings parallel official meetings or deliberations in formal chambers are supplemented by deliberations in offshore meetings.

After a few sessions of deliberation, the leaders of UNCITRAL's Transport Working Group realised that even with their fast start the pace of deliberation was so slow that any multilateral agreement would take many years to complete. The head of the US delegation pressed delegates to come up with a way to fast-track proceedings. The solution? Divide the issue area into separate topics, each of which prefigured a separate section in a prospective treaty. Ask a country delegation to lead an issue area. Invite delegates to join a network of people to work on that topic. And give every topical group/network a deadline to produce a draft set of issues and lawmaking responses. Sweden, Finland, the Netherlands, the United States and other countries each led a group that operated 'offline' and informally, far from UNCITRAL's formal proceedings, but which ultimately fed into formal deliberations and prefigured working group consensus on topics.

The move to multiply time might ordinarily be yet another opportunity for power to be exercised by large states or expert NGOs with the capacity to mobilise. Yet the means of multiplying time also provides an opportunity for weaker players on the global stage, not least when smaller informal groups and networks can offer a vocal delegate persuasive powers less readily exercised before the entire panoply of delegates and delegations.

\section{Time as resistance}

The ultimate arbiters of global convergence on norms are national states and local actors. Worlds of governance and regulation are replete with examples of elegant and ambitious global standard-setting efforts that remain global in name only. Norms and laws, regulations and standards remain on the books of IOs and fail to be adopted or implemented locally. The theories of recursivity of law and transnational legal orders are premised on the contingencies that inhibit settling of globally transmitted norms in local situations and that institutionalise not conformity but discordance between transnational and global norms, on the one hand, and national and local laws, regulations and ultimately behaviour, on the other (Block-Lieb and Halliday 2015). 
Comparative research demonstrates that so-called weak states have greater powers to foil the hegemons than is often supposed (Halliday and Carruthers 2007a). In fact, the efficacy of weapons of the weak frequently turns on the temporal qualities of lawmaking and implementation. Research reveals at least six ways that a politics of temporal manipulation gives supposedly weak states considerable power to determine their own fates in worlds of putative global governance.

\section{Delay}

The classic response of weak states to unwanted global norms and regulation is to adopt externally mandated or authorised norms in slow motion. States with limited infrastructure capacities, weak public administration, scarce supplies of expert civil servants and tiny private clusters of expertise can protest effectively to international monitors and IOs that state officials are very willing to comply, but, due to state incapacities, they simply cannot proceed very rapidly. Inspection of IMF quarterly reports on Indonesia's adoption of agreed-on reforms after the 1997-98 East Asian Financial Crisis reveals repeated postponements of progress on adopting and implementing reforms.

\section{Comply symbolically}

Symbolic compliance has long been identified as a means by which the objects of regulation or lawmaking gesture compliantly towards the regulators and lawmakers but, in practice, act deviantly. In effect, these methods are another way of playing for time.

- Implement partially: Here states implement something but not everything and that can lead to externally or internally (for example, interest groups, NGOs, social movement pressure) induced iterative rounds of further lawmaking, monitoring, feedback or regulatory tightening, all of which elongate time to implementation.

- Implement perversely: For example, hidden or detailed recommendations that come to light slowly and begin to take hold before international monitors, regulators or governors perceive their subversive capacities.

- Enact statutes, subvert through regulations: Statute books are more visible to global lawmakers and international monitors. Regulations, written in local languages, spread sometimes among multiple agencies and recorded in a shadowland far less accessible to IOs, which 
track up to 200 states across the world. As China's 1996 Criminal Procedure Law demonstrated, a new law with vague and potentially inconsistent terms, interpreted in disparate ways by multiple agencies (police, courts, prosecutors, and so on), draws out any likely settling of national norms and practice in accordance with global norms, and thereby offers local interests diverse ways to confound local or international norm-setters intent on legal change.

- Enact law, fail to enforce: Some global regulatory systems, such as the vast transnational legal order erected to combat money laundering and the financing of terrorism, place a premium on national compliance through law on the books or the creation of new administrative agencies, such as financial intelligence units. Every five years or so every country must undergo a country assessment. Knowing that five-year cycles provide windows of time in which law might become practice, countries can comply with law on the books, but the number of arrests, convictions, sentences or confiscations of funds can lag dramatically. By the time a country responds partially to its lagged law-in-practice, another five years may go by with marginal increments, which a country can then promise to improve in the next five years. All the while, countries buy time to implement selectively.

- Enact statutes, subvert courts: A similar logic can occur via the courts. Prosecutors may bring charges for money laundering but judges can fail to convict, sentence lightly or not at all or release convicted persons.

\section{Fragment international regulators and norm makers}

This tactic, when possible, provides another temporal challenge to national convergence on transnational norms. An effective foiling tactic for a state intent on noncompliance is to appeal to alternative or conflicting sets of transnational norms or standards. The most sophisticated of those international actors understand that conflicting norms and confusing signals from global centres will slow the impetus for change-certainly national and local change-towards convergence on standards or rules. This incipient power of weak states thereby contributes impetus for veteran IOs of all sorts to take more time in global lawmaking and regulation to achieve global consensus. An overt struggle between the World Bank and UNCITRAL, for instance, over whose global norms would constitute the gold standard for bankruptcy systems took years to resolve (Halliday and Block-Lieb 2013). In the final analysis, their 
agreement was induced because of strong pressure from the IMF and the US State Department and Treasury, who feared precisely the lack of certainty that would accompany competing global standards. In other words, to enable a faster pace of national and local implementation, global lawmakers had to tolerate a slower pace of negotiations among contesting IOs along the path to consensus.

\section{Segment reforms}

Just as IOs may break a potential stream of norms into a sequence of incremental products, so, too, states can segment reforms not only for progressive and deliberate implementation but also for delaying implementation. In the latter case, state lawmakers may break a single comprehensive reform into many small parts, each of which must then go through recursive cycles of lawmaking, partial implementation, further adaptive reforms and new efforts at implementation, until either new practices emerge or the legal change is abandoned as ineffective. International financial institutions suspected that this was South Korea's tactic following the 1997-98 East Asian Financial Crisis. The Government of South Korea enacted small statutory and administrative reforms at the pace of about one a year for several years, all the while postponing drafting and enactment of a comprehensive bankruptcy law that the international financial institutions believed they had been promised at the height of the crisis. Of course, the government might construe these small steps as prudent and incremental. To impatient global standard-setters, however, the promise of comprehensive reform seemed to be subtly receding into a dimly uncertain future.

\section{Invoke cultural incompatibilities}

From China to Indonesia and across the world, national and local lawmakers and law implementers make the argument-frequently true-that externally induced norms are so foreign to local customs and practices that formal adoption or practical implementation presents a formidable barrier to concordance with transnational and global norms. This argument can take an absolutist form-namely, that an overseas practice simply will not work, which was an argument made by Indonesian reformers who declared that adversarial tactics between debtors and creditors in corporate bankruptcy proceedings simply would not work in a conflict-averse Javanese or Indonesian culture. Such an argument can also take a temporal form - namely, that a country might 
be willing to try to bring its law and institutions into concordance with global norms, but it will take a very long time for it to seep into local legal and other consciousness, and therefore IOs should lower their expectations about the timing and scope of global regulatory impacts.

\section{Substitute a solution}

Any state may plausibly make the case that it concurs with the general principle of a reform concordant with global norms, but the specifics of implementing it might be better reconceived by national and local alternatives. Germany made this argument, for instance, to assessors from the Financial Action Task Force, which demanded that Germany adhere to the letter of the anti-money laundering international standard and not substitute an alternative it had asserted would be much better in local circumstances. Whatever the merits of Germany's case in this circumstance, the logic of alternative solutions remains plausible, even desirable. But, here again, time intrudes because global regulators, with their toolkits and templates in place, are inclined to retort: yes, your alternative might make sense, but how long can we wait until we find out? If you are wrong, and facts prove you are mistaken, years of regulatory impact are effectively lost. And, of course, in the realpolitik of regulatory conformity, the claim made by states for substitutionary alternatives may itself be a cynical attempt to play for time.

\section{Conclusion: The politics of time}

Time offers one of the most powerful weapons to be wielded by the weak in struggles over global governance, lawmaking and regulation. If the manipulation of time enables the strong to jockey for power at the global lawmaking centre, the politics of time endows the weak with a resource that is very difficult to overpower in global peripheries.

International lawmakers, the IMF and World Bank, regional development banks and international rights organisations are all impatient. For them, virtue inheres in the immediacy of action, in rapid conformity, in fast concordance of norms and short-term convergences of practice. In part, such impatience is a virtue borne of necessityIOs lose interest, shift priorities, lose resources or are dragged away to new paradigms or fresh crises. Their prospects for global impact are 
frequently momentary. And, even when they can be sustained for decades, IOs are never fully a match for the tactical powers of the so-called weak, whose patience by intent or incapacity invariably will outlast the strong.

Here, then, we are compelled to return to the varieties of grand time and events. Given epochal influences over the longue durée, ideologies or systems of coercive power or pervasive beliefs reinforced century after century will leach directly and indirectly into the localities of their spheres of influence. Even epochal events-a great war, horrific genocides, a worldwide depression-cast long temporal shadows, certainly of decades, occasionally of centuries. Global governance and regulation play themselves out in varieties of time. Historical time, organisational time and decision-making time-all are both backdrops to action and variously manipulable by differently situated actors. Research must consciously situate its subjects inside time of varying scale as it concomitantly searches for temporal agency by all the players in the great game of global governance and regulation.

\section{Further reading}

Greenhouse, CJ 1996. A Moment's Notice: Time Politics Across Culture. Ithaca, NY: Cornell University Press.

Pierson, P 2004. Politics in Time: History, Institutions and Social Analysis. Princeton, NJ: Princeton University Press. doi. org/10.1515/9781400841080.

Sassen, S 2000.'Spatialities and temporalities of the global: Elements for a theorization', Public Culture 12: 215-32. doi.org/10.1215/0899236312-1-215.

\section{References}

Abbott, A 2001. Time Matters: On Theory and Method. Chicago: University of Chicago Press.

Block-Lieb, S and Halliday, TC 2007. 'Incrementalisms in global lawmaking', Brooklyn Journal of International Law 32: 851-903. 
Block-Lieb, S and Halliday, TC 2015. 'Settling and concordance: Two cases in global commercial law settling in transnational legal orders-Corporate bankruptcy law and international trade by sea', in TC Halliday and G Shaffer (eds), Transnational Legal Orders. New York: Cambridge University Press, pp. 80-110. doi.org/10.1017/ CBO9781107707092.004.

Block-Lieb, S and Halliday, TC 2016. 'Contracts and private law in the emerging ecology of international lawmaking', in G Mallard and J Sgard (eds), Contractual Knowledge: A Hundred Years of Legal Experimentation in Global Markets. New York: Cambridge University Press, pp. 350-99. doi.org/10.1017/CBO9781316442876.011.

Block-Lieb, S and Halliday, TC (forthcoming 2017). Global Lawmakers: International Organizations in the Crafting of World Markets. New York: Cambridge University Press.

Braithwaite, J and Drahos, P 2000. Global Business Regulation. Cambridge: Cambridge University Press.

Braudel, F 1996. The Mediterranean and the Mediterranean World in the Age of Philip II. Berkeley: University of California Press.

Halliday, TC and Block-Lieb, S 2013. 'Global duelists: The recursive politics of the text in international commercial law', in A PerryKessaris (ed.), Sociolegal Approaches to International Economic Law: Text, Context, Subtext. London: Routledge, pp. 77-97.

Halliday, TC and Carruthers, BG 2007a. 'Foiling the hegemons: Limits to the globalization of corporate insolvency regimes in Indonesia, Korea and China', in C Anton and V Gessner (eds), Globalisation and Resistance: Law Reform in Asia Since the Crisis. Oxford: Hart Publishing, pp. 255-301.

Halliday, TC and Carruthers, BG 2007b. 'The recursivity of law: Global normmaking and national lawmaking in the globalization of bankruptcy regimes', American Journal of Sociology 112: 1135-202. doi.org/10.1086/507855.

Halliday, TC and Carruthers, BG 2009. Bankrupt: Global Lawmaking and Systemic Financial Crisis. Palo Alto, CA: Stanford University Press. 
Halliday, TC and Karpik, C 2012. 'Political liberalism in the British post-colony: A theme with three variations', in TC Halliday, L Karpik and MM Feeley (eds), Fates of Political Liberalism in the British Post-Colony: The Politics of the Legal Complex. New York: Cambridge University Press, pp. 3-58. doi.org/10.1017/ CBO9781139002981.002.

Halliday, TC and Shaffer, G (eds) 2015a. Transnational Legal Orders. New York: Cambridge University Press.

Halliday, TC and Shaffer, G 2015b. 'Transnational legal orders: A theoretical frame', in TC Halliday and G Shaffer (eds), Transnational Legal Orders. New York: Cambridge University Press, pp. 3-74. doi.org/10.1017/CBO9781107707092.002.

Halliday, TC and Shaffer, G 2015c. 'Researching transnational legal orders', in TC Halliday and G Shaffer (eds), Transnational Legal Orders. New York: Cambridge University Press, 473-528. doi. org/10.1017/cbo9781107707092.019.

Halliday, TC, Karpik, L and Feeley, MM (eds) 2012. Fates of Political Liberalism in the British Post-Colony: The Politics of the Legal Complex. New York: Cambridge University Press.

Halliday, TC, Levi, M and Reuter, P 2014. Global Surveillance of Dirty Money: Assessing Assessments of Regimes to Control Money Laundering and Combat the Financing of Terrorism. Chicago: Center on Law and Globalization, American Bar Foundation and University of Illinois College of Law.

Hathaway, OA 2005. 'Between power and principle: An integrated theory of international law', University of Chicago Law Review 72: 469-536.

Karpik, L 1998. French Lawyers: A Study in Collective Action, 1274-1994. Oxford: Oxford University Press.

Putnam, RD, with Leonardi, R and Nanetti, RY 1993. Making Democracy Work: Civic Traditions in Modern Italy. Princeton, NJ: Princeton University Press.

Schwartz, B 1975. Queuing and Waiting: Studies in the Social Organization of Access and Delay. Chicago: University of Chicago Press. 
This text is taken from Regulatory Theory: Foundations and applications, edited by Peter Drahos, published 2017 by ANU Press, The Australian National University, Canberra, Australia. 